\title{
News of MRS Members/Materials Researchers
}

Clyde L. Briant, dean of engineering and the Otis E. Randall University Professor at Brown University, has been appointed vice president for research, effective July 1. Briant succeeds Andries van Dam, the inaugural vice president for research.

J.M. Carpenter of the Intense Pulsed Neutron Source Division of Argonne National Laboratory has been named the recipient of the Neutron Scattering Society of America's 2006 Clifford G. Shull Prize for "seminal contributions to the development of neutron sources and instrumentation that have had worldwide impact on neutron scattering across a broad range of scientific disciplines, culminating in the optimized design of the Spallation Neutron Source at Oak Ridge."

Andrea Hill of NanoSonics Inc. has been named recipient of the Outstanding Young Engineering Alumnus Award for 2005-2006 by Virginia Polytechnic Institute and State University.
Yakov Kutsovsky has been named a vice president of Cabot Corporation.

Richard M. Laine has been appointed director of the University of Michigan Macromolecular Science and Engineering Center.

Doug Ray has been named associate laboratory director for the Fundamental Science Directorate at Pacific Northwest National Laboratory. Ray replaces Steve Colson, who is retiring.

Arthur H. Rosenfeld, a commissioner at the California Energy Commission, where he serves as chair of the Research and Development Committee and as the second member of the Energy Efficiency Committee, has been named the recipient of the 2005 Enrico Fermi Award, the U.S. government's oldest award for scientific achievement. This presidential award carries an honorarium of $\$ 375,000$ and a gold medal. The Department of Energy administers the Fermi Award on behalf of the White House.
Giacinto Scoles (Princeton University and the International School for Advanced Studies) and J. Peter Toennies (University of California, Berkeley; the Max Planck Institut; and the University of Göttingen) have been awarded the 2006 Benjamin Franklin Medal in Physics for the development of new techniques for studying molecules, including unstable species that could not be examined otherwise, by embedding them in extremely small and ultracold droplets of helium. Their work also led to a better understanding of the extraordinary properties of superfluid helium, such as its ability to flow without friction.

John Tranquada, head of the Neutron Scattering Group at the Department of Energy's Brookhaven National Laboratory, has been named the recipient of the 2006 Sustained Research Prize established by the Neutron Scattering Society of America.

\section{The Materials Gateway-www.mrs.org}

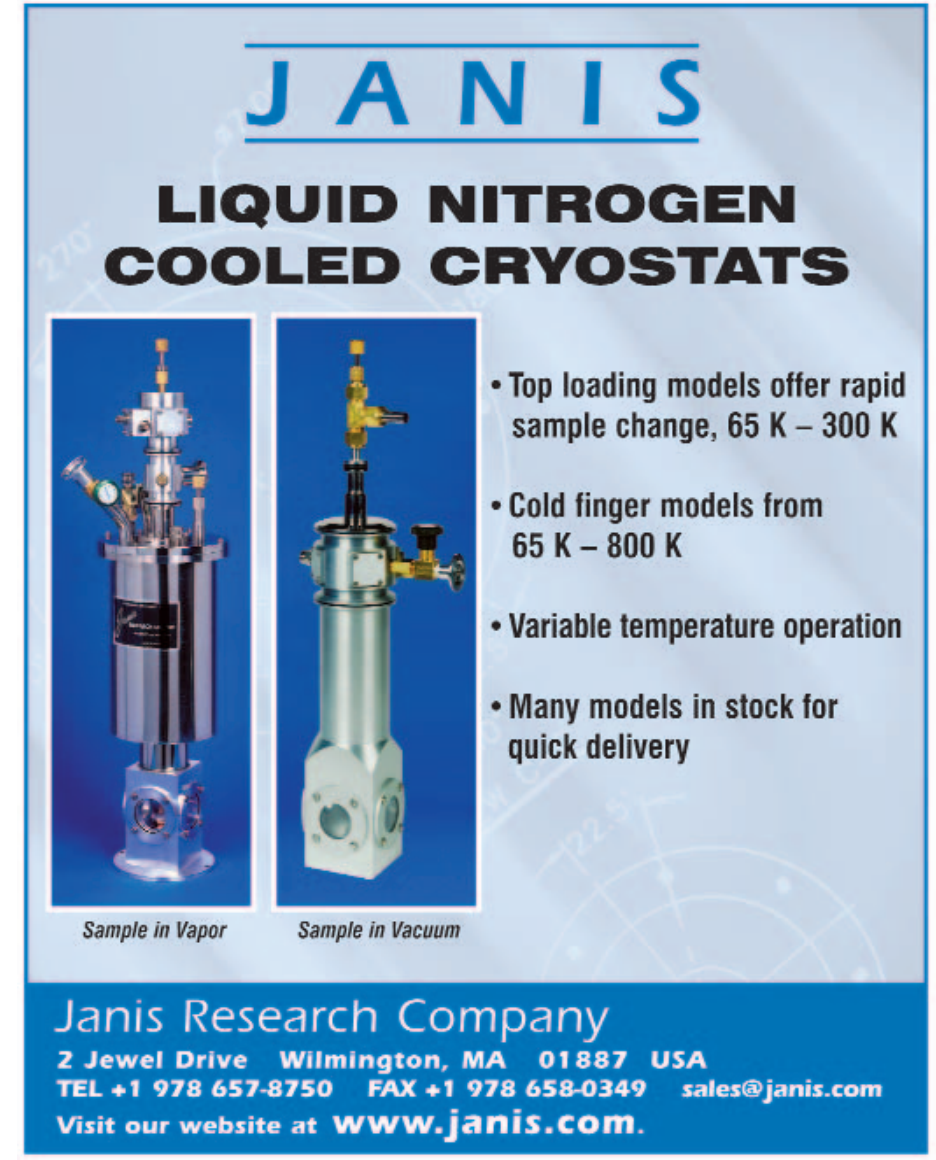

For more information, see http://www.mrs.org/bulletin_ads

\section{MRS Election Goes Online!}

The Material Research Society's

annual election of officers and

directors will be

\section{ONLINE}

this year to provide members

with an easier, more convenient

way to vote!
Watch your e-mail in July for further details: 